\title{
Using Theory to Inform Capacity-Building: Bootstrapping Communities of Practice in Computer Science Education Research
}

\author{
SALLY FINCHER \\ Computing Laboratory \\ University of Kent \\ Josh TENEnBERG \\ Institute of Technology \\ University of Washington, Tacoma
}

\section{AbSTRACT}

In this paper, we describe our efforts in the deliberate creation of a community of practice of researchers in computer science education (CSEd). We understand community of practice in the sense in which Wenger describes it, whereby the community is characterized by mutual engagement in a joint enterprise that gives rise to a shared repertoire of knowledge, artefacts, and practices.

We first identify CSEd as a research field in which no shared paradigm exists, and then we describe the Bootstrapping project, its metaphor, structure, rationale, and delivery, as designed to create a community of practice of CSEd researchers. Features of other projects are also outlined that have similar aims of capacity building in disciplinary-specific pedagogic enquiry. A theoretically derived framework for evaluating the success of endeavours of this type is then presented, and we report the results from an empirical study. We conclude with four open questions for our project and others like it: Where is the locus of a community of practice? Who are the core members? Do capacity-building models transfer to other disciplines? Can our theoretically motivated measures of success apply to other projects of the same nature?

\section{INTRODUCTION: PROBLEMATISING CSED RESEARCH}

The subject of computer science education (CSEd) research is an inevitably situated practice. It is situated within an institutional context, which dictates (among other things) quality assurance procedures and funding allocations; it is situated within a departmental context which depends on student intake, the chosen curriculum, and academic expectations; and it is situated within individual classrooms - these students, this topic — where teaching is an enactment of private, personal, and largely tacit beliefs about teaching and learning. For CSEd research to be viable, educators must be able to transfer from generalised results to the specifics of individual contexts. This requires that the research extend beyond the descriptive account of situated practice - the Marco Polo paper ("been there, done that"), the teaching tool report, and the nifty assignment exposition-that has characterized the bulk of CSEd research presented in the major CSEd teaching-practitioner conferences to date [1]. Though these accounts play important roles in teacher development and community self-definition, they do not constitute a theoretical base for CSEd.

The primary challenges in developing this base of CSEd research are sociological. There is as yet no paradigm of CSEd research. As Kuhn states [2]:

Effective research scarcely begins before a scientific community thinks it has acquired firm answers to the following: What are the fundamental entities of which the universe is composed? How do these interact with each other and with the senses? What questions may legitimately be asked about such entities and what techniques employed in seeking solutions?

"Normal" science takes place among scientific communities that have a shared set of answers to the above questions. Kuhn calls this socially shared set of beliefs a paradigm. Paradigms comprise a disciplinary community's ontology (what things we are concerned with), epistemology (how we may know things to be true), and methodology (how we find things out). These core beliefs inform, as well as constrain, the behaviour of workaday scientists.

Not having a shared paradigm for carrying out CSEd research means that the models of how established research communities work do not pertain. Because the subject matter requires both disciplinary knowledge and familiarity with research techniques of the human sciences, it is often the case that there are at most one or two staff members in any given department with the necessary knowledge and expertise. There are no specific "meeting places" (conferences, societies, publications and citations) where researchers can gather together and form the identity of the work through recognition and acknowledgement [3], no places where newcomers can join in at the periphery [4]. There are few doctoral programs to provide a "way in," to introduce and define the research landscape and form and maintain the research networks. And since there are no acknowledged centers for this research, there are no concentrations of researchers. This in turn means there are none of the "invisible colleges" that link researchers with shared backgrounds - who have worked on projects together in the past, or who have undertaken doctoral work in the same institutionbut who are now dispersed to different institutions [5].

Without an established paradigm, the CSEd researcher must enter a Trading Zone where intellectual and methodological borrowings are necessarily made from a number of disciplines. This metaphor is used by Peter Galison [6] in discussing the disparate traditions from which modern physics (conceived as an intellectual discipline) stems. As Fincher and Petre state "It may be that every 
interdisciplinary field is a 'trading zone' (or grows from one). For CS education, we must learn to speak with our trading partners" [7] which includes the social and learning sciences, and the disciplinaryeducation research of cognate disciplines (e.g., mathematics education, physics education).

There are two consequences worth noting of CSEd research being a trading zone. The first is that being a Trading zone researcher is higher risk than being a paradigmatic researcher (taking the evolutionary epistemology perspective [8]): mechanisms for research selection and reproduction (publications, grants, tenure, graduate students) cannot be taken for granted as it can for the paradigmatic researcher. Questions about disciplinary survival (e.g., Where do I publish? Can I obtain external funding? Will I get tenure?), are always present. Whereas answers are tacitly understood by scientists within established paradigms, they become both explicit and unanswered when the CS Ed trading zone is entered.

The second consequence concerns the epistemological and methodological ecumenicalism required of the trading zone researcher. Within an established research paradigm, the accepted methods for establishing truth are taken for granted: "Men whose research is based on shared paradigms are committed to the same rules and standards for scientific practice" [2, p11]. Although tacitly shared, these methods are not invisible. Rather, they are externalized, reified, in the protocols, instruments, tools, and publications of the community of researchers. The practice and reifications thus reflect and reproduce the assumptions shared by the members of the community. In the trading zone however, borrowings are pragmatically driven - one uses methods as demanded by the research question [7]. The advantage of this pragmatic stance is the range of methods that can be brought to bear on any particular problem. The disadvantage is in the reconciliation of the different methods and traditions, some of which may be in sharp contrast to each other in epistemological assumptions. As Wenger points out [9], "The work of reconciliation may be the most significant challenge faced by learners who move from one community of practice to another." For the individual entering the trading zone, undergoing deliberate processes of knowledge construction and experiencing epistemological vertigo, having a community of peers, fellow-researchers mutually engaged in the same enterprise, becomes essential to the individual's ability to carry out research and persist in doing so.

\section{THE BOOTSTRAPPING METAPHOR: INDIVIDUAL, COMMUNITY OF PRACTICE, AND BROADER RESEARCH COMMUNITY}

It was in response to these historical and sociological problems in doing CSEd research that we developed the Bootstrapping project. The bootstrapping metaphor is both humble and reflexive, "pulling oneself up by the bootstraps", and additionally has a specific meaning within computing. "In computers, this term refers to ... processes whereby a complex system emerges by starting simply and, bit by bit, developing more complex capabilities on top of the simpler ones." [10]

In naming our project, we used the metaphor in three distinct senses, reflecting our goals to impact three distinct, though interacting, levels:

- bootstrapping the novice CSEd researcher by providing entry points into the theory and methods of carrying out CSEd research;
- bootstrapping a community of practice of CSEd research practitioners with similar skills, practices, and language for engaging in shared research endeavours; and

- bootstrapping the wider CSEd research community by establishing a critical mass of researchers with rigorous practices and standards for carrying out and evaluating CSEd research.

By bootstrapping simultaneously at all three levels, the effort is mutually reinforcing, thereby contributing to normalization of CSEd as a distinct and rigorous research paradigm and simultaneously hastening individuals' full participation. We viewed the community of practice, the middle level, as the most important: a bridge from the individual to the emergent discipline as a whole. This community would (we hoped) serve as an incubator of research ideas, a source of collaborators and critics, and a space for research discourse in which study designs and interpretations could be rehearsed and contested before taking them to the forums of the broader research community. Hence, our primary efforts were geared toward the creation and sustenance of a community of practice.

But how does one create a community of practice when none exists? What are the characteristics that determine this sort of community from any other group? Neighbourhood communities require geographical co-location, kinship communities require ties of blood and reciprocal obligation, but communities of practice must have shared practice. Consequently, we were deliberate in our design to create interventions that establish and sustain practices. In Communities of Practice: Learning, Meaning E Identity, Wenger identifies "three dimensions of the relation by which practice is the source of coherence of a community" (p. 72, 73). We used these as key design principles. These dimensions are:

1. Mutual Engagement-Membership in communities of practice is enacted through the dynamic and continuous interactions on issues of shared interest and meaning.

2. Joint Enterprise-Community is sustained through emergent projects and plans that the members themselves negotiate and hold one another accountable to.

3. Shared Repertoire-Through mutual engagement on shared enterprises, members develop a shared set of "routines, words, tools, ways of doing things, stories, gestures, symbols, genres, actions or concepts that the community has produced or adopted in the course of its existence and which have become part of its practice" ( $\mathrm{p} 83$ ).

These are delicate points of balance and peril in terms of design; too heavy-handed an approach can stifle, or even destroy, the practices we seek to support. They represent crucial terms of engagement for enabling community to emerge from practice. In the Bootstrapping-model we addressed these as very practical issues and created a sequence of designed activities to sustain "enough mutual engagement in pursuing an enterprise together to share some significant learning" (p. 86) creating the "shared histories of learning" that Wenger claims characterize communities of practice that extend over time.

\section{Project Design AND STRUCTURE}

The Bootstrapping model has the following major constituents:

- Workshops-Intensive four-day workshops attended by approximately 20 international CS educators in two successive years. 


\begin{tabular}{|c|c|}
\hline Year 1 Workshop & $\begin{array}{l}\text { Introduction to CSEd research. } \\
\text { Presentation of the experiment kit. }\end{array}$ \\
\hline Interim & $\begin{array}{l}\text { Participant execution of the experiment kit at home institution. } \\
\text { Participant preparation of a sketch for a new research study. } \\
\text { One-half day "check-in" meeting at national CSEd conference mid-year. } \\
\text { Electronically-mediated communication (e-mail list, password-protected Web } \\
\text { site) }\end{array}$ \\
\hline Year 2 Workshop & $\begin{array}{l}\text { Conclusion of the experiment kit: collaborative presentation, amalgamation, and } \\
\text { analysis of data; writing up. } \\
\text { Framing of individual research studies. }\end{array}$ \\
\hline
\end{tabular}

Table 1. Sequence of Bootstrapping-model activities.

- Experiment Kit-A shared empirical research study in CSEd carried out by each participant in the intervening year between the workshops.

- Individual Scaffolding-The scaffolding for participants to undertake new research studies in CSEd.

The Bootstrapping-model was first implemented in 2002 with a cohort of 21 participants ${ }^{1}$ from five countries (United States, Wales, Ireland, Australia, and New Zealand). Participants were recruited at CSEd conferences and via CSEd e-mail lists. A grant from the National Science Foundation supported costs of workshop attendance for participants from the U.S. and workshop leaders, but participants were not otherwise paid for attendance. The activities that constitute the model are summarized chronologically in Table 1 , and each of the major parts is then described in more detail below. Participants committed to the entire sequence of activities at the time of acceptance. The model was implemented with a second cohort beginning in 2003 with 18 participants $^{2}$ from four countries (United States, Wales, Sweden, and New Zealand). This paper reports on both cohorts.

\section{A. Workshops}

As in all work of this kind, it was clear that we would have to bring people together in a "workshop" situation. However, we were also clear about the problems of the one-shot workshop model: participants come, attend, and are enthused, but on return to work, out of the exclusive focus of the workshop environment and away from the support of workshop leaders and other participants, the demands of normal life assert themselves as enthusiasm and momentum fade. This would not build the sup-

${ }^{1}$ The institutions represented by participants from the first cohort were as follows. All are in the U.S.A except where noted. University of Washington, University of Virginia, Saint Louis University, Metropolitan State University, Blue Ridge Community College, University of Wisconsin-Parkside, Xavier University, University of Technology, Sydney (Australia), College of Charleston, Drake University, Southern Polytechnic State University, Pacific Lutheran University, UNITEC Institute of Technology (New Zealand), Vassar College, Rhode Island College, University of Northern Colorado, University of Limerick (Ireland), University of Wales, Aberystwyth (UK), University of Arizona, University of Washington-Bothell.

${ }^{2}$ Pacific Lutheran University, Pomona College, University of WashingtonTacoma, Saint Joseph's University, Uppsala University (Sweden), Montclair State University, University of Connecticut, California State University Long Beach, Umea University (Sweden), Tufts University, University of Wales, Aberystwyth (UK), University of Otago (New Zealand), Northwest Missouri State University, Roosevelt University, University of San Diego, Azusa Pacific University, Georgia Institute of Technology, University of Washington-Seattle. portive, on-going community we sought. Consequently, we created a different workshop structure: we would have the traditional workshop, away from e-mail and other distractions, but we would then have a second workshop the following year. However, we did not believe this expectation of return was, in itself, enough, so we designed a piece of work that all participants would undertake, in their own classrooms, in the intervening year between the workshops. We chose to call this an "experiment kit." In this way, we worked to foster the mutual engagement of the participants.

1) Workshop One: Workshop one was topic-oriented. The intention was to provide an overview of CSEd research and to enable participants to think about how to do research in CS education. Participants came to the workshop with considerable depth in the field of computer science, with experience as teaching practitioners, and with their discipline-specific methodological and epistemological biases toward theory construction and validation. They had insight into the CS education issues that are interesting to investigate, but without the skills and experience in educational research to allow them to undertake such investigations. Each workshop day was themed (day one, "Putting research methods in context," day two, "How to ask questions and how to seek answers," day three, "Working from purpose to technique," and day four, "Introduction to, and practice with, the experiment kit") and contained a combination of delivered material, guided discussions, and practical exercises. Additionally, each day, there was time for participants to consider their own research questions as a way of reflecting on the material to date.

2) Intervening Year: In the year between the two workshops, participants undertook the research study defined in the experiment kit, designed so that each participant undertook the same study in their own classrooms and institutional contexts.

While community cannot be built remotely, it can be sustained at a distance. Execution of the experiment kit was one of the ways in which we fostered the experience of joint enterprise. The participants in their separate, although co-ordinated, acts of conducting the experiment kit research mutually negotiated community meaning. This started with the necessity for every participant to obtain Human Subjects clearance-participants exchanged war stories, tips and tricks, and paragraphs of text to overcome the first hurdle. Then they talked about how many subjects they had obtained, who had the most, who thought they were unlikely to get enough to "make the cut" (a minimum was required). As well as providing the 
infrastructure for these exchanges (mailing lists and passwordprotected project Web pages for the collection and collation of data) the workshop leaders also organized an interim meeting colocated with one of the major practitioner conferences (the ACM/SIGCSE Technical Symposium On Computer Science Education). Attendance at the second workshop was conditional on completing the experiment kit work, on contributing data to the collective. If an individual did not do this, they were not allowed back: participation in the joint enterprise was mandatory.

3) Workshop Two: Workshop two was task-oriented, focussed on two tasks. First, the group worked to analyze the aggregated data from the experiment kit, and jointly write a paper to report it. Second, each participant worked on a design for his or her own research study. In contrast to workshop one, most of the input in this workshop was from the participants, presenting and discussing their experiences of using the experiment kit to completion, and reflecting on research in general. The tasks of the workshop leaders were in structuring interventions to maximize the effectiveness of the analysis and writing, within the compressed time frame of four workshop days, and in working with participants on their new study designs.

\section{B. The Experiment Kit}

What we have called an "experiment kit" is a research problem defined by a principal investigator (in this case the workshop leaders). It details the design of a relevant study from methodology to analysis, and situates the study in its theoretical context (readings, case studies, and further references). The experiment kits used in instantiations of the Bootstrapping model include material that details the study's focal questions and the reasoning behind them. They describe the pilot studies undertaken and situate the work in the context of relevant literature and underlying theoretical and methodological approaches and assumptions [11].

An experiment kit should contain everything an individual researcher needs to understand and undertake their portion of the study, including all material to be given to the study participants, copies of papers which are core reference material for the investiga- tion (as well as pointers to further reading), specification of the format in which data is to be collected, specification of the information required about each participating institution, and some indication of the types of analysis that will be undertaken. A table of contents from a Bootstrapping model experiment kit is provided in Table 2 . The kits themselves are available online [12].

The experiment kit used with the first cohort was focused on the conceptual foundations of programming skills in first- and secondyear undergraduate students. We were interested in whether students make sense of such terms as iteration and decomposition and whether they form abstractions such as data structure or language paradigm. The main method chosen for data gathering was the repeated, single-criterion card sort, a well-known knowledge elicitation technique used within the expert systems community [13]. On completion, the resultant data corpus contained 275 research subjects from 21 institutions from six countries, making it one of the largest research studies ever undertaken in CSEd, notable not only for its size but for being multi-institutional and multi-national in breadth.

The experiment kit used with the second cohort was focused on understanding characteristics of student-generated software designs, student recognition of requirement ambiguities, and students' valuation of key design criteria. The main method for data gathering [12] consisted of (1) creation (by the study participants) of a paper-and-pencil software design representation in response to a given design brief, (2) a semi-structured interview in which study participants described their design, and (3) a design criteria prioritization task, in which study participants ranked a set of design criteria (representing such things as maintainability, coupling, cohesion) in terms of importance relative to different scenarios. There were 314 subjects from 21 institutions in four countries within the data corpus, again one of a small handful of studies of this size ever undertaken within the field.

One of the ultimate aims of Bootstrapping was that it would graduate people who could design and work on their own smallscale studies, but that was an impossible goal for the intervening

\begin{tabular}{ll}
\hline 1. & Question formulation \\
\hline 2. & Protocol \\
& a. Data collection specification \\
& b. Human Subjects materials \\
& c. Background questionnaire \\
& d. Discriminator question \\
& e. Specification of set-up \\
& f. Experimenters script (including guidance on notes/diagramming) \\
& g. Participant design brief \\
& h. Design criteria elicitation Stimuli set \\
& i. Design criteria elicitation Recording Sheet \\
\hline 3. & Analysis protocol \\
\hline $4 . \quad$ & Background (including details of pilot studies) \\
\hline $5 . \quad$ Literature \\
\hline
\end{tabular}

Table 2. Atypical table of contents from a Bootstrapping-model experiment kit. 
year. Not only is that precisely the kind of activity that suffers from "post-workshop" isolation, but also the participants were not research-mature enough to act as constructive support for each other (in a design-critique-iterate model). The shared study provided experience of what doing disciplinary-education research means, and entails, in its specifics; therefore, making participants work on the same research question (of our devising) had several advantages.

First, pragmatically, we could design the study in advance. We could be fairly sure that it would "work", that there would be results, and we were not reliant on the chance of participants bringing workable ideas with them. Second, it required the use and practice of research skills, not just "book learning." Third, undertaking the study that the kit defined gave participants a consistent and comparable experience. The experiment kit (and its execution) became an object to which everyone had an interface; it gave common vocabulary, common experience and common identity. The experiment kit became a shared "boundary object" [9, p.105] which defined the scope and reified the work of the Bootstrapping community.

\section{Scaffolding Research Skills}

A considerable amount of expertise is embedded within the structure of any empirical study design. This includes knowledge (both tacit and explicit) of the costs of data gathering, the reliability of various elicitation methods, the fitness of different methods for addressing different questions, and the methodological confidence required of the researcher to carry out data gathering and analysis. In the Bootstrapping model, we scaffolded the development of these requisite skills and knowledge in several ways.

First, during both workshops, participants were provided with "theoretical pitons" for conceptualizing the major steps of an entire piece of research, from conception through design and enactment to publication, drawn from the "Six Guiding Principles of Scientific Research" detailed in Scientific Research in Education [14]. Although we consider research to be as often bottom-up and pragmaticallydriven as it is top-down and hypothesis-driven, these idealized principles nonetheless provide clear identification of the constituent parts of the majority of empirical research studies. Additionally, this was a published work, widely and easily accessible, and well-known to educational researchers. Thus, it provided a transferable vocabulary, and could serve as a transition between the workshop presentations and experiences, and emergent research work in the individual's local context.

A second scaffold was to actively engage participants in each of the identified research steps, only undertaking their own study designs after first "walking through" many of these steps in the context of the experiment kit.

Third, we did not regard individual study design as a private process. In our view research takes place within a community of researchers. Particular research communities determine the range of questions that its members pursue, the kind of evidence that is accepted to adjudicate claims, and the methods that are used for acquiring evidence. Our aim would not be fulfilled if participants grappled with their research questions (and the operationalisation of them into studies) silently and alone.

As leaders, therefore, we had to model and scaffold questiongeneration and study design as a public process, open to debate, scrutiny, critique, and acclaim. Within the workshops, a primary mechanism we used for this was "the wall." Simply, "the wall" consisted of a poster-sized piece of paper for each participant stuck on the wall of the room. During each day of the year one workshop time was devoted to working "on the wall", identifying areas of interest, refining these to questions, searching for appropriate evidences and techniques. Participants used pens, drawings, and postit notes to create these living documents. Because "the wall" was always there and always available, many discussions became physically located with the record of the ideas. People would "walk the wall", reading and commenting on others' work at scheduled times, but also at break times or before sessions started. Participants with similar interests could move their posters together; sometimes "extra" posters spawned between existing work or for investigating new, joint, projects. Many of these behaviours have been noted in similar environments of radical co-location as "project rooms" or "war rooms"; see [15]. Most valuable to us was the fact that discussions at "the wall" were semi-public: although they occurred with the poster-owner and were about their specific work, the type of conversation, the style of question and nature of enquiry, all foundational to research discourse, were always observable, overhearable, and in some sense community property.

Finally, on the last day of the year two workshop, all participants publicly presented the designs of their new studies. From each design we captured several attributes: some concrete (such as number of subjects, proposed techniques for data-gathering), some that required estimation (cost of planning, cost of execution, cost of analysis) and some evaluative (strength of evidence). In this way aspects of study design that are often opaque to novice researchers were exposed, and the process clearly demonstrated that elements of study design are not independent; that high cost in one area (planning, say) might be traded-off with low cost in another (analysis, perhaps).

We considered it to be important that this was not a private exercise nor was it a "master class" where only the experts critique the students, but a community practice. Individuals were the only ones able to describe the concrete aspects of their designs, but everyone was able to contribute an evaluative opinion. Thus, comments were offered from the floor, such as "good" for "strength of evidence", but also the less flattering "constrained" or "strong in limited context." It was clear that participants could assess how and where designs were weak with comments such as "should be higher" against "cost of planning." All participants saw all studies, heard all critiques, and in the process, built a sense of calibration: what constitutes work in this domain that we find acceptable, that satisfies the questions we ask of it.

These were very specific and situated aspects of our designing for a community of practice. Edwin Hutchins notes

"limits on observation of the activities of others have consequences for the knowledge acquisition process. This is so because they define the portion of the task environment available as a learning context to each task performer. Let us refer to the outer boundary of the portion of the task that can be seen or heard by each team member as that person's horizon of observation" [16, p.52]

By our use of "the wall" and the "design trade-offs" elicitation, we brought community practices within the horizon of observation of every participant and in this way concretely modelled scholarly and community discourse in disciplinary-specific pedagogic research. 


\section{OTHER MODELS OF CAPACITY BUILDING IN ENGINEERING EDUCATION RESEARCH}

As well as activity in the broad area of capacity-building, for example, the various activities of the Center for the Advancement of Scholarship on Engineering Education at the U.S. National Academy of Engineering [17], two specific capacity-building models in engineering education research subsequent to Bootstrapping have emerged. Their existence evidences the perception that engineering education, alongside computer science education, also requires a cadre of engineering educators skilled in disciplinary-specific pedagogic enquiry.

- The Conducting Rigorous Research in Engineering Education (RREE) project, supported by NSF funding, has run workshops in 2004/5, 2005/6 and 2006/7. Each annual RREE workshop consists of a single week-long meeting. During this time participants develop individual studies, which they continue working on after the workshop, on a one-to-one basis with a research mentor. RREE participants receive $\$ 2,000$ “mini-grants" to support the projects they develop.

- The NSF-funded Center for the Advancement of Engineering Education has, as one of its components, established annual Institutes for Scholarship on Engineering Education (ISEE). These have run in 2004/5, 2005/6, and 2006/7. ISEE cohorts are a mix of faculty and graduate students who each undertake individual studies that are set in the context of the investigation of a learning issue derived from their own teaching. Each Institute starts with a week-long co-located workshop, and participants maintain contact over the year.

Although there are similarities (and differences) in the model of delivery, these initiatives share common aims to one another and to Bootstrapping. To reiterate, the objectives of Bootstrapping (2002/3 and 2003/4) were "to improve the state of Computer Science education research ... by developing skills (in the design, conduct, and management of research) of Computer Science educators" and "to facilitate the establishment of research relationships that extend beyond the duration of the workshops, contributing to a research community able to sustain a constructive discourse as well as ongoing collaboration" [8].

The RREE series has the twin goals to: "Create and present workshops for engineering faculty on conducting rigorous research in engineering education," and to "Sustain the development of this project through establishing a community of practice" [19]. RREE reinforce this latter goal with their logo, consisting of a Venn diagram with three, intersecting circles. The three circles are labelled "Engineering Educators," "Learning Scientists," and "POD: the Faculty Developers network." These are clearly separate communities with separate constituencies, memberships and practices. The intersection of these, however, is labelled "The Community of Practice."

For ISEE, "The main goal is to foster a diverse cadre of leaders and change-agents in engineering education who can conduct high impact research" [20] through "developing community networks for supporting long term professional growth and fulfilment" [21].

It is striking that all three of these capacity-building projects bring people together for a "workshop" with two primary goals: individual skill development in carrying out disciplinary-specific education research, and the creation of a "community" of such researchers. How then do we measure the success of these endeavours?

\section{V.MEASURES OF SUCCESS}

In seeking criteria for success in Bootstrapping it seems likely that our chosen measures could apply to these other Bootstrapping-like endeavours, which share similar aims and so, presumably, seek similar outcomes.

In seeking metrics for success, we identified two areas of interest. The first was to use exactly the same indicators that are commonly used to measure research capacity and outputs: publications and replications. Because we are interested in community, as well as counting these outputs, we also calculated the "connectedness" of research collaborations that they represent. As all this material is freely available in the public domain, we call these "visible indicators."

Publications, however, tell only one part of the story. Communities are not sustained by their outputs, but by the practices that produce those outputs. Consequently, we undertook a qualitative enquiry into the research practices of the Bootstrapping participants. Because these are not readily apparent to the outside world, we call these "invisible indicators."

By examining these visible and invisible indicators together, we argue in the next section that Wenger's three dimensions of community (mutual engagement, joint enterprise, and shared repertoire) are continuing features of the Bootstrapping community of practice.

\section{Visible Indicators}

1) Publications: If one of the aims of a project is to help participants undertake disciplinary-specific educational research, then whether they are doing that might be measured by what we term "visible" indicators, those overt signs of participation in the discourse via normal academic routes: workshops, panels, posters and papers at conferences, papers in journals, and grants awarded.

Wherever an output has been subject to peer review, we count it as evidence that Bootstrapping graduates have proved their competence in the domain. The CSEd research publications subsequent to Bootstrapping, 31 to January 2006 (listed in appendix A), cover the spectrum of type of publication (extended abstract, panel at a conference, workshop, conference paper, journal paper). All have been submitted to, and accepted in, peer-reviewed venues. The Bootstrapping papers also appear in the particular places where CSEd research is commonly published, i.e., those places where people interested in CSEd research would naturally seek it. By this simple count, we believe Bootstrapping to be successful.

2) Network Density: A common measure of the degree of social connectedness among a group of people is the sociogram [22], which uses a graph structure to encode relationships between pairs of individuals. In the sociogram, a person is represented as a graph node, and a tie (or relationship) between two people is represented by an arc between the two nodes corresponding to this pair of people. Ties can be characterized by strength: "the strength of a tie is a (probably linear) combination of the amount of time, the emotional intensity, the intimacy (mutual confiding), and the reciprocal service which characterize the tie" [22, p. 1361]. Network density is the proportion of existing ties to possible ties [23], i.e., a real number between zero (indicating no ties) and one (indicating a tie between each pair of individuals).

A sociogram of the Bootstrapping participants has 41 nodes. Thirty-eight of these nodes represent the participants in the two cohorts (20 and 18, respectively), and three nodes represent the workshop leaders. There are 820 possible pairwise ties (each of 41 people 
having a tie to the other 40 people, divided by half due to symmetry). Under the assumption that co-authorships indicate strong ties, a paper with $n$ co-authors creates $n(n-1) / 2$ strong ties.

The publications that resulted directly from the experiment kit analysis during the second workshop of each cohort [24, 25] had 23 and 22 co-authors, respectively. The resulting sociogram would thus have 968 strong ties out of the possible 820 . These two papers alone result in a network density of 0.59 , i.e., ties representing 59 percent of the possible pairwise relationships between the 41 participants. Including the five papers that involved cross-cohort coauthorship (since the remaining 24 papers duplicate strong ties within the same cohort), the network density considering all publications is 0.6 .

Excluding the papers co-authored by the entire cohort, the resulting network density among the 41 participants is still 0.12 , a surprisingly high level of activity considering that these publications represent new research performed after returning from the intensive workshops. Most of these collaborations involved individuals from different institutions and, in some cases, different countries. These densities are calculated only on strong ties; if weak ties are considered (the occasional e-mail query, the brief encounter at a conference), then the networks are much more dense, though we did not systematically gather data about weak ties. Finally, of the 31 peerreviewed papers, 15 include authors who did not take part in either cohort of Bootstrapping, thus providing evidence of the influence of the workshops beyond the boundaries of the Bootstrapping community of practice. By these sociometric measures, there is every appearance that Bootstrapping is successful.

3) Replication: An evolutionary metaphor, involving selection and replication with variation, has been used as a metaphor by historians and sociologists of science to understand the growth of scientific knowledge within disciplinary communities [8]. Replication and adaptation of the model can be taken as a separate indicator of success: that is, the model is successful to the extent that it is reproduced (perhaps with variation).

The Bootstrapping model was instantiated a third time in Australasia (as Building Research in Australasian Computing Education: BRACE [26]) organised by two co-ordinators (one a participant of the first Bootstrapping cohort, one a participant of the second) and including the original workshop leaders. Bootstrapping participants have also adapted the model in new projects: the "Leeds Working Group" [27] (organised by a Bootstrapping participant and containing members from each of the three Bootstrapping instantiations) and BRACELeT [28], an extension of the BRACE project (see appendix B). The model will be instantiated a fourth time in the Swedish CeTUSS-sponsored project Stepping Stones in 2006/7. [29]. One of the original Bootstrapping leaders, and one of the ISEE workshop leaders will run the Stepping Stones workshops. A further elaboration of these replications can be found in [11]. Thus, in terms of replication, we believe the Bootstrapping model is successful.

However, these visible indicators represent the proverbial oneeighth of the iceberg that floats above the water. In terms of the practice(s) that define a research community, they represent- they are a token of - other activity. This leads directly to the question of how to evidence community, if not by these visible indicators? Because we are very close to the individuals that make up the Bootstrappers we were able to gather data on the direct activities, which the tokenisation of publication encapsulates.

\section{E. Invisible Indicators}

Although accepted publications represent research activity, they do not represent the whole of that activity. On enquiry, we found not only the inevitable rejected papers, but also several other indicators that leave less public (although by no means less important or less archival) traces. We sent a solicitation to the Bootstrapping email list (representing all members of both cohorts), requesting information about the participants' invisible collaborations, those not yet (or perhaps ever) yielding the visible indicators described above. We gave examples of possible such collaborations (verbatim from our solicitation):

- paper or grant reviewing (where the "collaboration" is between reviewer and organizer)

- letters of reference

- co-organizing and/or participation in panels and workshops that do not leave traces (e.g., discussants at doctoral consortia)

- attempts to generate visible outcomes that did not bear out (e.g., papers submitted but not accepted, grants not funded)

- current collaborations directed toward visible indicators that have not yet born fruit (publications, grants).

We stated that there are "undoubtedly additional collaborations that some of you have undertaken not indicated in the above list."

We received responses from 29 of the 38 participants from both cohorts. The data that resulted from our solicitations were many and varied, but some common categories emerged: local effect, professional activity, further collaborations, and professional service.

Quotations have been anonymised as to identity, but we have preserved gender in the names, and used forename only where the respondent used forename only, forename and family name where they used forename and family name. We have not made a one-toone mapping of names to pseudonyms in order to preserve the anonymity of the participants so no correlation may be expected between the quotations. Spelling and case have been preserved throughout. Typically, the first cohort refer to themselves as "Bootstrappers", the second as "Scaffolders"; the neologism "bootscaff" represents the collective of both instantiations.

1) Local Effect: A number of participants were not replicating in the large (in replication or adaptation of the model, as Replication above), but were working in their local context to extend and support their CSEd research interests:

"Following Bootstrapping, I started a local CSEd research group with faculty in my department at Poppleton

University. I would not have had the confidence to do this without the Bootstrapping background."

As well as explicit mechanisms such as forming groups, other participants reported more implicit effects in their departmental environment:

"Also, I feel that I am more respected in my department. Even though research is not a required component of my position, I have been well-supported by my department head and colleagues and am seen as the local expert on questions about performing studies ..."

2) Professional Activity: As well as the purely local effects, many participants talked of engagement with the broader research 
community as mediated by their Bootstrapping contacts. Reviewing for conferences, and especially journals, was mentioned as valuable in this context:

"I have been a reviewer for Computer Science Education twice now. Neither would have happened without Bootstrapping."

Other activities that participants mentioned included conference organisation and grant reviewing:

"I helped Neville review some papers for his CCSC conference last year. I'm an external evaluator for a CCLI grant run by Hermione, one of Ron's colleagues. Ron recommended me for the position because of our bootscaf connections, and Hermione considered me qualified as a result of my participation."

Overt acknowledgement of expertise was welcomed in this professional context (here by being asked to work on a CSEd Doctoral Consortium) and participants were conscious of the need to "pass on the professional baton" to others in the community:

"I review for Computer Science Education (I think that is because of meeting Dorothy) and was on doctoral consortium (thanks to Harriet). I then brought Peter in, but then he turned into a Scaffolder so that only sort-of enlarged the community."

3) Further Collaborations: Active research collaborations and joint efforts in defining areas of enquiry are activities that generate the visible indicators of participation and build the mutual relationships and result in further engagement. Bootstrapping has already generated a number of subsequent projects (for example [30]) which have resulted in publication. However, it is clear that this activity is still on-going. Here are three representative examples:

"Another large group is meeting weekly online, doing a literature review on debugging and related topics. It is currently lead by Fiona Ackley and includes from west to east, Edmond, me, Sarah Perkins, Jane Roberts, Grant Chen, Victoria Kaupe, John Kacerowski, and Claudia LaFarge."

It is worthwhile noting that this collaboration represents five time zones on three continents. The following two quotations refer to another project (and for coherence we have preserved consistent naming between the two speakers here):

Malachi says "I meet up on a weekly basis with Henning, Florence, Errol, Sybil and Ermintrude." and Henning says "I'm meeting almost every week with Ermintrude, Malachi, Errol, Sybil, Florence and James to do some research"

In these reports we see that whilst the members of this subnet are distributed, "meet" is not predicated by "online" and no longer used metaphorically. These reports take for granted the separation of the participants by several thousand miles, four time zones and the mediating electronic environment that enables them so casually to "meet."

A third collaborative project described by one respondent demonstrates appropriating the opportunity offered by existing events to organize face-to-face collaborations. These meetings result from multiple members of the community being present on other professional occasions, such as attending conferences, or serving on grant review panels (as in Professional Activity, above)

"Can-do" project: Participants: Susan Hunt, Sarah Broadleaf, Thomas Silverstone, Harry Shumway, Syd Green, Darlene Capulet. Description: Trying to understand what students know (i.e., what knowledge teachers can potentially leverage off of) before they start taking CS courses. Initial data includes student responses when asked to describe (in complete sentences) how to sort a list of 10 numbers. Status: Outlined the project in July, 2005 (at NSF CCLI panel reviews in DC), initial data collected early in the fall semester/quarter, discussion of initial data in September, 2005 (day before ICER in Seattle), more data being collected to be discussed within next few months (hopefully).

4) Professional Service: Participants also called on each other to provide external opinion in professional contexts. This represents a qualitatively different category of indicator as it requires institutional acceptance, approbation and/or validation, in addition to the private and personal regard participants may have for each other.

"I served on Bramwell's promotion committee. I have written other promotion letters for people in the community."

"Jane wrote me a tenure letter. I wrote a tenure letter this fall for Charlotte."

"I was able to have Gene as the Ph.D. examiner for my student."

By the measures of ongoing practice that these "invisible indicators" evidence, we believe Bootsrapping to be a successful model.

\section{F. Wenger's Three Dimensions of Community (Reprise)}

We have argued that Wenger's three dimensions of mutual engagement, joint enterprise and shared repertoire distinguish a community of practice from other forms of community, social network, or "constituencies without a shared practice" [9, p. 103]. We have also presented Bootstrapping as a model for building research capacity, and claim that it creates a community of practice. We now examine how the measures by which we judge the success of our enterprise are embodied within these dimensions.

Mutual Engagement. The "further collaborations" subsequent to Bootstrapping, some of which have been shown above, provide the basis for continued mutual engagement in the practices of a research community. The measures of professional activity and professional service typify mutual engagement between practicing researchers. Additionally, the opportunistic use of other professional events to support face-to-face encounters ("discussion of initial data in September, 2005 (day before ICER in Seattle)") shows a commitment to continued engagement.

Joint Enterprise. Bootstrapping in itself, and the collective undertaking of the experiment kits in particular, were clearly joint enterprises for each cohort. All participants but one completed data collection, 
returned for the second workshop, and participated in data analysis and the writing of research results - joint enterprise was thus enacted. By undertaking new and ongoing collaborative research, participants demonstrate the use of "joint enterprise" as a learned practice.

Shared Repertoire: A shared repertoire has proven more important to the subsequent identity of the community than to its formation, although some of the details of that formation turned out to be key elements that helped form identity. There was simply the fact of having been through the same experience, akin perhaps to having been to the same school or joined the same club:

"I did meet Charles Ryder, a Scaffolder, here. That was interesting because he said he felt an instant brotherhood with me the instant he learned I am a Bootstrapper. We traded stories and so forth. It seems the experience has created a community"

However, there were also more subtle indicators, where participants drew on their shared repertoire to identify intellectual "kin" with whom they could trust to reciprocate effort directed toward joint research goals:

"Having had the experience of following through is big. I don't want to invest my (scarce) time and energy in collaboration unless I have confidence that my collaborators will follow through as well. Knowing that I am dealing with people who I have either already worked with, or I know have followed through with a [Bootstrapping] related project, makes me more likely to start new collaborations with them, and thus more likely to start CSEd research collaborations in general."

\section{G. Boundaries Between Communities}

No one belongs only to a single community: multi-membership is the norm. The indicators we identify above evidence characteristics internal to the Bootstrapping community, but at the same time they define articulations with other external communities to which individuals also belong.

Many of these articulations are negotiated as Bootstrapping participants integrate new knowledge and practice with their existing institutional and professional relationships. They then become brokers between communities, bringing their newfound skills and confidence in CSEd to their local settings (e.g., research groups and curricula efforts) and to the broader CSEd community (e.g., panel organization and conference reviews). "Brokers are able to make new connections across communities of practice, enable coordination, and-if they are good brokers-open new possibilities for meaning" [9, p. 109]

What we observe is that in the process of becoming a member of the Bootstrapping community, of gaining competence with community practices and discourse, participants take back these practices to existing communities. In so doing, they validate the knowledge and practices that forge their connection with the other Bootstrapping participants, while strengthening and redefining their membership in existing, external communities.

This brokerage, however, is not one-way; it is not only in terms of taking back (of knowledge, of practice, of discourse) to external communities, but also a drawing from these external communities. Already, of the 31 Bootstrapping publications, 15 have named co-authors who were not Bootstrapping participants. Each new replication of the Bootstrapping model expands the boundary of the Bootstrapping community of practice. The Bootstrapping model was designed to encourage this sort of brokering behaviour by recruiting from those already engaged in CSEd, by scaffolding practices to extend beyond the boundaries of the workshop context, and by linking to theoretical knowledge from reference disciplines. The form in which it emerged was also surprising in the variety and number of ways in which participants linked their Bootstrapping-acquired knowledge to external communities. It is this brokering that most clearly demonstrates how bootstrapping a community of practice can, at the same time, bootstrap individual competence and the broader community of CSEd researchers.

Evidencing "community", let alone "community of practice" is problematic. Nevertheless, we believe that using a theoreticallymotivated framework affords projects such as these a way to distinguish activities along interesting and useful dimensions.

\section{OPEN QUESTIONS}

While we have identified several indicators of success aligned with Wenger's three dimensions of coherence for a community of practice, nevertheless, there remain open questions:

1. Where is the locus of Bootstrapping? It is clear that, at one time, Bootstrapping existed in a time and place. Subsequently, as the community members disperse, it is increasingly hard to say "where" Bootstrapping exists. It may be concentrated in the various activities of community members, or it may coalesce in the observed opportunistic appropriation of other professional events to support face to face encounters (as Further Collaborations, above). These further meetings and collaborations also indicate expansion of the community to include "outsiders" additional to original members. It is hard to tell what effect these dilutions may have. Without an identifiable locus of interaction, it may be that community ties will weaken and the community itself disperse over time. This question will likewise apply to the capacity-building efforts in engineering education research described above (i.e., RREE and ISEE) once the workshops end and the participants disperse.

2. Who are the core members of the Bootstrapping community of practice? Wenger [31] describes a feature of communities as having central and peripheral members. For Bootstrapping, however, we question this model's simplicity. There are no "old-timers" in the sense that anyone has been in this community longer than anyone else. Each participant has their own sense of their participation, and brings their own meaning to it (although the tenor and flavour of these individual senses are not discordant). It would be hard to define criteria to judge who are the central members of the Bootstrapping community versus those at the periphery. Those who have the most publications (the high producers in Crane's invisible colleges [5]) versus those who have the least? Those with the most collaborations versus those with the fewest? The most unique collaborations - "I did a quick scan the other day and noticed that I've collaborated with every one of the Bootstrappers except Vincent since Bootstrapping (and I've corresponded with him)"-versus those with none or none that they care to share? Those who have 
initiated the most subsequent replicative or adaptive projects versus those who have participated in them? Any one of these candidate criteria might describe a center, or central participant, and in doing so would put some participants there and others further away. Which one might be more accurate, or useful, is unclear. For the disciplinary-specific education research communities of practice built de novo, such as Bootstrapping, ASEE, and ISEE, the distinction between core and periphery is not straightforward, and may only manifest its importance at later stages of community maturity.

3. Does this model transfer to other disciplines? Bootstrapping as we did at three levels (individual, community of practice, and broader research community) was in response to the sociological and historical context in which CSEd currently exists. For instance, though pre-paradigmatic, there were nonetheless individual researchers already doing excellent research in CSEd, and fledging efforts at building fora for the dissemination of results. In addition, there was an active community of computer science educators with regular meeting places and publication venues. It was from this group that the project participants were drawn and it was back to these same venues that much of the research generated by participants would be targeted. These same contextual factors arguably exist for engineering education as well. We were also fortunate that project participants were not doctrinaire in their approach toward research in the learning sciences, exhibiting an epistemological and methodological flexibility consistent with the pragmatic approach to research design that the workshops advocated. But might the pragmatic approach that we experienced be more strongly resisted if the participants had come from a discipline with more rigid paradigmatic practices for investigating social and behavioural truth claims? For example, would anthropologists seeking to study their own classrooms be willing to abandon ethnography in favour of, for example, surveys and focus groups, or the use of large-scale statistical analyses? Having done so, would they find an audience among either educators or other educational researchers within anthropology? Would the disciplinary ways of knowing [32] from one of the source disciplines serve as an entry point, a head start into doing disciplinary education research, serving as an advantage rather than a hindrance?

4. Can our theoretically-motivated measures of success apply to other projects of the same nature in engineering education? While it is our intention that they do, our measures can only be applied to projects that are suitably mature and have sufficient public accounting to populate the framework and allow meaningful comparison along these dimensions: Bootstrapping is older than either RREE and ISEE, and has data beyond initial instantiation.

We see two distinct advantages of attempting to generalize these measures beyond the bounds of any single capacity-building endeavour. First is to work towards the development of transferable principles to provide heuristic guidance in the deliberate creation of research communities; uncovering the relationship between specific characteristics of an intervention and subsequent outcomes will certainly be a necessary prerequisite for defining such principles. Second, we are hopeful that for those brokers of communities of practice with goals consonant to Bootstrapping, considering measures of success that link intervention to outcome will help in the design of such capacity-building efforts. At least we hope it might sensitise such brokers to the non-obvious indicators of a vital community, which might otherwise go unnoticed.

\section{ACKNOWLEDGMENTS}

Part of this material is based upon work supported by the $\mathrm{Na}$ tional Science Foundation (NSF) under grants numbered DUE0243242 and DUE-0122560. Any opinions, findings, conclusions or recommendations expressed in this material are those of the authors and do not necessarily reflect the views of the NSF.

Marian Petre worked with us on the initial model, and we gratefully acknowledge her significant input. Anthony Robins and Patricia Haden read drafts of this paper and provided us with useful and insightful commentary.

We particularly wish to thank the participants in the Bootstrapping workshops who continue to evolve their practice, enact community, and replicate the model.

\section{REFERENCES}

[1] Valentine, D.W., CS Educational Research: A Meta-Analysis of SIGCSE Technical Symposium Proceedings, in 25th SIGCSE Symposium on Computer Science Education, Norfolk, Va.: ACM Press, 2004.

[2] Kuhn, T.S., The Structure of Scientific Revolutions, Chicago, Il.: University of Chicago Press, xv, p. 172, 1962

[3] Becher, T., Academic Tribes and Territories: Intellectual Enquiry and the Cultures of Disciplines, Milton Keynes: Society for Research into Higher Education Open University Press, xiii, 200 p., 1989.

[4] Lave, J., and E. Wenger, Situated Learning: Legitimate Peripheral Participation, Cambridge, England: Cambridge University Press, 1v, 1991.

[5] Crane, D., Invisible Colleges: Diffusion of Knowledge in Scientific Communities, Midway reprints, Chicago, Il.: University of Chicago Press, x, p. 213, 1988.

[6] Galison, P.L., Image and Logic: A Material Culture of Microphysics, Chicago, Il.: University of Chicago Press, xxv, p. 955, 1997

[7] Fincher, S., and M. Petre, eds., Computer Science Education Research, London, England: Routledge Falmer, 2004.

[8] Radnitzky, G.E., and W.W.E. Bartley, Evolutionary Epistemology, Rationality and the Sociology of Knowledge, La Salle, I.: Open Court, 1987.

[9] Wenger, E., Communities of Practice: Learning, Meaning, and Identity, Learning in Doing, Cambridge, U.K.; New York, N.Y.: Cambridge University Press, xv, p. 318, 1998.

[10] Wikipedia, available from: http://en.wikipedia.org/wiki/Bootstrapping.

[11] Fincher, S., R Lister, T. Clear, A. Robins, J. Tenenberg, and M. Petre, in Proceedings of the First International Computing Education Research Workshop, ICER'05, pages 111-121, SIGCSE, ACM, September 2005, Seattle, Wa.

[12] Experiment Kit Page, [cited 16 January 2006]; available from: http://www.cs.kent.ac.uk/people/staff/saf/experiment-kits/, 2005.

[13] Rugg, G., and P. McGeorge, The Sorting Techniques: A Tutorial Paper on Card Sorts, Picture Sorts, and Item Sorts, Expert Systems, 1997, 14(2).

[14] Shavelson, R.J., and L. Towne, Scientific Research in Education,Washington, D.C.: National Academy Press, xiii, p. 188, 2002. 
[15] Olson, G.M., and J.S. Olson, "Distance Matters," HumanComputer Interaction, Vol. 15, No. 2/3, 2000, pp. 139-178.

[16] Hutchins, E., "Learning to Navigate," in Understanding Practice: Perspectives on Activity and Context, S. Chaiklin and J. Lave, eds., Cambridge University Press: Cambridge, p. 35-63, 1996.

[17] Center for the Advancement of Scholarship in Engineering Education (CASEE), 2002.

[18] Bootstrapping Research in Computer Science Education, available from: http://depts.washington.edu/bootstrp/, 2002.

[19] Rigorous Research in Engineering Education, available from: http://www.mines.edu/research/cee/ND.htm, 2004.

[20] Center for the Advancement of Engineering Education, available from: http://www.engr.washington.edu/caee/research_elements.html, 2003.

[21] Institute for Scholarship on Engineering Education 2006-07, available from: http://www.engr.washington.edu/caee/isee-2006-07.html, 2006.

[22] Granovetter, M., "The Strength of Weak Ties," American Journal of Sociology, Vol. 76, No. 8, 1973, pp. 1360-1380.

[23] Burt, R., "The Network Structure of Social Capital," Reseach in Organizational Behavior, Vol. 22, 2000.

[24] K. Sanders, S. Fincher, D. Bouvier, G. Lewandowski, B. Morrison, L. Murphy, M. Petre, B. Richards, J. Tenenberg, L. Thomas, R. Anderson, R. Anderson, S. Fitzgerald, A. Gutschow, S. Haller, R. Lister, Raymond, R. McCauley, J. McTaggart, C. Prasad, T. Scott, Terry, D. ShinnersKennedy, S. Westbrook, C. Zander, K. Sanders, "A Multi-Institutional, Multinational Sstudy of Programming Concepts Using Card Sort Data," Expert Systems, Vol. 22, No. 3, 2005, pp. 121-128.

[25] Fincher, S., P. Marian, J. Tenenberg, K. Blaha, D. Bouvier, T-Y. Chen, D. Chinn, S. Cooper, A. Eckerdal, H. Johnson, R. McCartney, A. Monge, J.E. Mostrom, K. Powers, M. Ratcliffe, A. Robins, D. Sanders, L. Schwartzman, B. Simon, C. Stoker, A.E. Tew, T. VanDeGrift, “A Multinational, Multi-institutional Study of Student-generated Software Designs," in Kolin Kolistelut. 2004, Koli, Finland.

[26] Building Research in Australasian Computing Education, available from: http://www.cs.otago.nz/brace, 2004.

[27] Lister, R., E. Adams, S. Fitzgerald, W. Fone, J. Hamer, M. Lindholm, R. McCartney, J.E. Moström, K. Sanders, O. Seppälä, B. Simon, L. Thomas, "A Multi-National Study of Reading and Tracing Skills in Novice Programming," Proceedings, ITiCSE 2004, Leeds, U.K.: ACM Press, 2004.

[28] Whalley, J., R. Lister, E. Thompson, T. Clear, P. Robbins, P.K. Kumar, C. Prasad, "An Australian Study of Reading and Comprehension Skills in Novice Programmers, Using the Bloom and SLO and SOLO Taxonomies," Proceedings, Eighth Australasian Computing Education Conference (ACE 2006), Hobart, Tasmania, 2006.
[29] Stepping Stones, available from: http://www.it.uu.se/research/ group/cetuss/events/2006-06/, 2005.

[30] Murphy, L., R. McCauley, S. Westbrook, T. Fossum, S. Haller, B.B. Morrison, B. Richards, K. Sanders, C. Zander, and R.E. Anderson Murphy, "A Multi-Institutional Investigation of Computer Science Seniors' Knowledge of Programming Concepts," Proceedings, 36th SIGCSE Technical Symposium on Computer Science Education, St Louis, Missouri, USA, 2005.

[31] Wenger, E., R.A. McDermott, and W. Snyder, Cultivating Communities of Practice: A Guide to Managing Knowledge, Boston, Ma.: Harvard Business School Press, 2002, xii, p. 284.

[32] Hativa, N., and M. Marincovich, Disciplinary Differences in Teaching and Learning: Implications for Practice, San Francisco, Ca.: Jossey-Bass Publishers, 1995.

\section{AUTHORS' BIOGRAPHIES}

Sally Fincher is a senior lecturer in the Computing Laboratory at the University of Kent where she leads the Computing Education Research Group. She holds a B.A. in Philosophy and Computer Science (University of Kent, UK) and an M.A. in English (Georgetown University, Washington DC). She is Editor of the journal Computer Science Education, jointly with Renée McCauley. Her principal research areas are Computer Science Education, the scholarship of teaching and learning, and patterns and pattern languages, especially patterns for interaction design.

Address: Computing Laboratory, University of Kent, Canterbury, Kent, CT2 7NF, United Kingdom; e-mail: s.a.fincher@kent.ac.uk.

Josh Tenenberg is professor in the Computing and Software Systems program in the Institute of Technology at the University of Washington, Tacoma. He holds a B.M. in music performance (San Francisco State University, U.S.A.) and an M.S. and Ph.D. in Computer Science (University of Rochester, U.S.A), where his primary research was in Artificial Intelligence. His research areas have included automated planning, knowledge representation and reasoning, reinforcement learning, temporal logic, and cognitive modeling of computer programming. Most recently, his research is in Computer Science Education, the scholarship of teaching and learning, and interaction design.

Address: Computing and Software Systems, Institute of Technology, University of Washington, Tacoma, Campus Box 358426, 1900 Commerce St, Tacoma WA 98402-3100; e-mail: jtenenbg@u.washington.edu. 


\section{APPENDIX A}

Refereed CSEd publications by Bootstrapping participants stemming from the Bootstrapping experiment kits and resulting collaborations, to January 2006.

Note that all participants of the first cohort as are named as authors in publication number 29 , and all participants of the second cohort are named as authors in publication number 30 . The workshop leaders appear as authors on both those publications.

1. Vicki Almstrum, Reneé McCauley, Suzanne Westbrook, Sally Fincher. Computer Science Education Research as a Scientific Endeavor. Grace Hopper Celebration of Women in Computing, Chicago, USA, 2004.

2. Ken Blaha, Alvaro Monge, Dean Sanders, Beth Simon, and Tammy VanDeGrift. Do students recognize ambiguity in software design? A multi-national, multi-institutional report. In ICSE '05: Proceedings of the International Conference on Software Engineering, 2005.

3. Dennis Bouvier, Gary Lewandowski, and Terry Scott. Developing a computer science education research program. The Journal of Computing Sciences in Colleges, Volume 19(1):217, October, 2003.

4. Tsu-Yi Chen, Stephen Cooper, Robert McCartney, and Leslie Schwartzman. The (relative) importance of software design criteria. In ITiCSE '05: Proceedings of the 10th Annual Conference on Innovation and Technology in Computer Science Education, Monte da Caparica, Portugal, June 2005.

5. Tzu-Yi Chen, Alvaro Monge, and Beth Simon. Relationship of early programming language to novice generated design. Proceedings of the 37th SIGCSE Technical Symposium on Computer Science Education, Houston, Texas USA, 2006.

6. Donald Chinn, Phil Prins, and Josh Tenenberg. The role of the data structures course in the computing curriculum. The Journal of Computing Sciences in Colleges, 19(2):91-93, 2003.

7. William Collins, Josh Tenenberg, Raymond Lister, and Suzanne Westbrook. The role for framework libraries in CS2. In SIGCSE '03: Proceedings of the 34th SIGCSE Technical Symposium On Computer Science Education, pages 403-404, New York, NY, USA, 2003. ACM Press.

8. Kate Deibel, Richard Anderson, and Ruth Anderson. Using edit distance to analyze card sorts. Expert Systems, 22(3):129138, 2005.

9. Anna Eckerdal, Robert McCartney, Jan-Erik Moström, Mark Ratcliffe and Carol Zander. Comparing student software designs using semantic categorization. In 5th Annual Finnish / Baltic Sea Conference on Computer Science Education, Koli Calling, 2005.

10. Anna Eckerdal, Robert McCartney, Jan Erik Moström, Mark Ratcliff, and Carol Zander. Can graduating students design software systems? SIGCSE '06: Proceedings of the 37th SIGCSE technical symposium on Computer science education, 2006.

11. Sally Fincher, Raymond Lister, Tony Clear, Anthony Robins, Josh Tenenberg, and Marian Petre. Multi-institutional, multi-national studies in CSEd research: some design considerations and trade-offs. In First International Computing Education Research Workshop (ICER '05), 2005.
12. Sally Fincher, Marian Petre, Josh Tenenberg, Kend Blaha, Dennis Bouvier, Tzu-Yi Chen, Donald Chinn, Stephen Cooper, Anna Eckerdal, Hubert Johnson, Robert McCartney, Alvaro Monge, Jan Erik Moström, Kris Powers, Mark Ratcliffe, Anthony Robins, Dean Sanders, Leslie Schwartzman, Beth Simon, Carol Stoker, Alison Elliott Tew, and Tammy VanDeGrift. A multinational, multi-institutional study of student-generated software designs. In 4th Annual Finnish / Baltic Sea Conference on Computer Science Education, Koli Calling, 2004.

13. Sally Fincher and Josh Tenenberg. Making sense of card sorting data. Expert Systems, 22(3):89-93, 2005.

14. Timothy Fossum and Susan Haller. Measuring card sort orthogonality. Expert Systems, 22(3):139-146, 2005.

15. Timothy Fossum and Susan Haller. Assessment: a new quantitative assessment tool for computer science programs. In ITiCSE '05: Proceedings of the 10th Annual Conference on Innovation and Technology in Computer Science Education, Monte da Caparica, Portugal, June 2005.

16. Sandy Garner, Patricia Haden and Anthony Robins. My program is correct but it doesn't run: a preliminary investigation of novice programmers' problems. Proceedings of the Seventh Australasian Computing Education Conference (ACE2005), pages 173-180. Newcastle, Australia, 2005.

17. Paul Gross and Kris Powers. Evaluating assessments of novice programming environments. In First International Computing Education Research Workshop (ICER '05), 2005.

18. Gary Lewandowski, Alicia Gutschow, Robert McCartney, Kate Sanders, and Dermot Shinners-Kennedy. What novice programmers don't know. In First International Computing Education Research Workshop (ICER '05), 2005.

19. Raymond Lister, Ilona Box, Briana Morrison, Josh Tenenberg, and Suzanne Westbrook. The dimensions of variation in the teaching of data structures. In ITiCSE '04: Proceedings of the 9 th annual SIGCSE conference on Innovation and technology in computer science education, pages 92-96, New York, NY, USA, 2004. ACM Press.

20. Robert McCartney and Kate Sanders. What are the "Threshold Concepts" in Computer Science? In 5th Annual Finnish/ Baltic Sea Conference on Computer Science Education, Koli Calling, 2005.

21. Renee McCauley, Laurie Murphy, Suzanne Westbrook, Susan Haller, Carol Zander, Timothy Fossum, Kate Sanders, Briana Morrison, Brad Richards, and Ruth Anderson. What do successful computer science students know?: an integrative analysis using card-sort measures and content analysis to evaluate graduating students' knowledge of programming concepts. Expert Systems, 22(3):139-146, 2005.

22. Laurie Murphy, Renee McCauley, Suzanne Westbrook, Brad Richards, Briana Morrison, and Timothy Fossum. Women catch up: gender differences in learning programming concepts. Proceedings of the 37th SIGCSE Technical Symposium on Computer Science Education, Houston, Texas, USA, 2006.

23. Laurie Murphy, Renee McCauley, Suzanne Westbrook, Timothy Fossum, Susan Haller, Briana Morrison, Brad Richards, Kate Sanders, Carol Zander and Ruth Anderson. A multi-institutional investigation of computer science seniors' knowledge of programming concepts. Proceedings of the 
36th SIGCSE technical symposium on Computer science education, St. Louis, Missouri, USA, pages 510-514, 2005.

24. Laurie Murphy, Brad Richards, Tammy VanDeGrift, and Brent Wilson. Models for Computer Science K-12 Outreach Activities, The Journal of Computing Sciences in Colleges, 12(1):274-276, 2005.

25. Laurie Murphy and Josh Tenenberg. Do computer science students know what they know?: A calibration study of data structure knowledge. In ITiCSE '05: Proceedings of the 10th Annual SIGCSE Conference on Innovation and Technology in Computer Science Education, New York, NY, USA, 2005. ACM Press.

26. Kris Powers, Paul Gross, Steve Cooper, Kenneth Goldman, and Martin Carlisle. Tools and environments for teaching introductory programming: what works? In Proceedings of the 37th SIGCSE Technical Symposium on Computer Science Education, Houston, Texas, USA, 2006.

27. Christine Prasad, Kathryn Sanders, and John McTaggart. Decoding programming concepts in eal and efl students: Is there a difference? In Proceedings of the Seventeenth Annual Conference of the National Advisory Committee on Computing Qualifications, pages 169-174, 2004.

28. Anthony Robins, Patricia Haden and Sandy Garner Problem Distributions in a CS1 Course. Proceedings of the Eigth Australasian Computing Education Conference (ACE2005). Hobart, Australia, 2006.

29. Kate Sanders, Sally Fincher, Dennis Bouvier, Gary Lewandowski, Briana Morrison, Laurie Murphy, Marian Petre, Brad Richards, Josh Tenenberg, Lynda Thomas, Richard Anderson, Ruth Anderson, Sue Fitzgerald, Alicia Gutschow, Susan Haller, Raymond Lister, Renee McCauley, John McTaggart, Christine Prasad, Terence Scott, Dermot Shinners-Kennedy, Suzanne Westbrook, and Carol Zander. A multi-institutional multinational study of programming concepts using card sort data. Expert Systems, 22(3):121-128, 2005.

30. Josh Tenenberg, Sally Fincher, Ken Blaha, Dennis Bouvier, Tzu-Yi Chen, Donald Chinn, Stephen Cooper, Anna Eckerdal, Hubert Johnson, Robert McCartney, Alvaro Monge, Jan Erik Moström, Marian Petre, Kris Powers, Mark Ratcliffe, Anthony Robins, Dean Sanders, Leslie Schwartzman, Beth Simon, Carol Stoker, Alison Elliott Tew, and Tammy VanDeGrift. Students designing software: A multi-national, multi-institutional study. Informatics in Education, 4(1):143-162, 2005.

31. Josh Tenenberg and Laurie Murphy. Knowing what I know: An investigation of undergraduate knowledge and self-knowledge of data structures. Computer Science Education, 15(4), 2005.

\section{APPENDIX B}

Refereed CSEd publications stemming from replications and adaptations of the Bootstrapping model that includes at least one Bootstrapping author.

\section{H. BRACE}

1. Michael de Raadt, Margaret Hamilton, Raymond Lister, Jodi Tutty, Bob Baker, Ilona Box, Quintin Cutts, Sally Fincher, John Hamer, Patricia Haden, Marian Petre,
Anthony Robins, Simon, Ken Sutton, Denise Tolhurst Approaches to learning in computer programming students and their effect on success. Annual International Conference of the Higher Education Research and Development Society of Australasia (HERDSA). Sydney, Australia, 2005.

2. Simon, Quintin Cutts, Sally Fincher, Patricia Haden, Anthony Robins, Ken Sutton, Bob Baker, Ilona Box, Michael de Raadt, John Hamer, Margaret Hamilton, Raymond Lister, Marian Petre, Denise Tolhurst, Jodi Tutty. The ability to articulate strategy as a predictor of programming skill. Eighth Australasian Computing Education Conference (ACE2006). Hobart, Australia, 2006.

3. Simon, Sally Fincher, Anthony Robins, Bob Baker, Ilona Box, Quintin Cutts, Michael de Raadt, Patricia Haden, John Hamer, Margaret Hamilton, Raymond Lister, Marian Petre, Ken Sutton, Denise Tolhurst, Jodi Tutty. Predictors of success in a first programming course. Eighth Australasian Computing Education Conference (ACE2006). Hobart, Australia, 2006.

4. Denise Tolhurst, Bob Baker, John Hamer, Michael de Raadt, Margaret Hamilton, Raymond Lister, Jodi Tutty, Ilona Box, Quintin Cutts, Sally Fincher, Patricia Haden, Marian Petre, Anthony Robins, Simon, Ken Sutton. Do map drawing styles of novice programmers predict success in programming?: A multi-national, multi-institutional study. Eighth Australasian Computing Education Conference (ACE2006). Hobart, Australia, 2006.

\section{BRACELeT}

1. Jacqui Whalley, Raymond Lister, Errol Thompson, Tony Clear, Phil Robbins, Ajith Kumar, and Christine Prasad. An Australian study of reading and comprehension skills in novice programmers, using the Bloom and SOLO taxonomies. Eighth Australasian Computing Education Conference (ACE2006). Hobart, Australia, 2006.

\section{J. Leeds Working Group}

1. Sue Fitzgerald, Beth Simon, and Lynda Thomas. Strategies that students use to trace code: an analysis based in grounded theory. In First International Computing Education Research Workshop (ICER '05), 2005.

2. Raymond Lister, Elizabeth S. Adams, Sue Fitzgerald, William Fone, John Hamer, Morten Lindholm, Robert McCartney, Jan Erik Moström, Kate Sanders, Otto Seppälä, Beth Simon, and Lynda Thomas. A multi-national study of reading and tracing skills in novice programmers. In ITiCSEWGR '04: Working group reports from ITiCSE on Innovation and technology in computer science education, pages 119-150, New York, NY, USA, 2004. ACM Press.

3. Robert McCartney, Jan Erik Moström, Kate Sanders, and Otto Seppälä. Questions, annotations, and institutions: observations from a study of novice programmers. In Proceedings of the Fourth Finnish/Baltic Sea Conference on Computer Science Education, pages 11-19, Koli, Finland, October 2004. Helsinki University of Technology, Department of Computer Science and Engineering, TKO-A42/04.

4. Robert McCartney, Jan Erik Moström, Kate Sanders, and Otto Seppälä. Take note: the effectiveness of novice programmers' annotations on examinations. Informatics in Education, 4(1):69-86, 2005. 